\title{
Correlation of genotype and phenotype in 32 patients with hereditary hemochromatosis in China
}

Liyan $\mathrm{Wu}^{1,2+}$, Wei Zhang ${ }^{1,2+}$, Yanmeng Li ${ }^{2,3}$, Donghu Zhou ${ }^{2,3}$, Bei Zhang ${ }^{2,3}$, Anjian Xu ${ }^{2,3}$, Zhen Wu ${ }^{1,2}$, Lina Wu ${ }^{1,2}$, Shuxiang $\mathrm{Li}^{1,2}$, Xiaoming Wang ${ }^{1,2}$, Xinyan Zhao ${ }^{1,2}$, Qianyi Wang ${ }^{1,2}$, Min Li ${ }^{4}$, Yu Wang ${ }^{1,2}$, Hong You ${ }^{1,2}$, Jian Huang ${ }^{1,2,3^{*}}$, Xiaojuan Ou ${ }^{1,2^{*}}$ and Jidong Jia ${ }^{1,2^{*}}$

\begin{abstract}
Background: Hereditary hemochromatosis $(\mathrm{HH})$ is widely recognized and clinical manifestations of hemochromatosis-related (HFE-related) HH is well studied in European populations. Less is known about the clinical and laboratory characteristics of non-HFE related HH in Asian population. We aimed to explore the relationship between genotype and clinical phenotype in Chinese patients with non-HFE related hereditary hemochromatosis.

Methods: Peripheral blood samples and clinical data of patients with primary iron overload were collected from the China Registry of Genetic/Metabolic Liver Diseases. Sanger sequencing was performed in cases with primary iron overload, for 5 known HH related genes (HFE, HJV, HAMP, TFR2 and SLC4OA1) and 2 novel iron homeostasis-related genes (DENND3 and SUGP2). The correlation of genotype and clinical phenotype in these patients was analyzed.

Results: Of the 32 patients with primary iron overload (23 were males and 9 were females), non-HFE variants were detected in 31 (31/32, 97\%), including 8 pathogenic variants in HJV, 7 pathogenic variants in SLC4OA 1, 8 likely pathogenic variants in SUGP2 and 5 likely pathogenic variants in DENND3 cases. Among these 31 cases, 4 cases harbored homozygous variants, 2 cases harbored homozygous + heterozygous variants, 19 cases harbored heterozygous or combined heterozygous variants, and 6 cases harbored no any damaging variants. None of investigated cases carried damaging HAMP and TFR2 variants were found. 8 cases were classified as type $2 \mathrm{AHH}$ and 6 cases as type 4 $\mathrm{HH}, 10$ cases as non-classical genotype, and 6 cases had no pathogenic variants from 31 cases. During the statistical analysis, we excluded one case (SLC40A1 IVS3 + 10delGTT + SUGP2 p. R639Q(homo)) with difficulty in grouping due to combined damaging variants. Cases with type $2 \mathrm{~A} \mathrm{HH}$ have an earlier age at diagnosis $(p=0.007)$. The iron index of cases in type $2 \mathrm{~A} \mathrm{HH}$ and type $4 \mathrm{HH}$ was higher than that in other groups $(p=0.01)$. Arthropathy was relatively rare in all groups. None of cases with type $2 \mathrm{~A} \mathrm{HH}$ developed cirrhosis. Cirrhosis and diabetes are more prevalent in type $4 \mathrm{HH}$. The incidence of cirrhosis $(p=0.011)$, cardiac involvement $(p=0.042)$, diabetes $(p=0.035)$ and hypogonadism ( $p=0.020$ ) was statistically significant in the four groups. However, due to the limited sample size, the pairwise comparison showed no significant difference.
\end{abstract}

\footnotetext{
*Correspondence: huangj1966@hotmail.com; ouxj16@126.com; jia_ jd@ccmu.edu.cn

${ }^{\dagger}$ Liyan Wu and Wei Zhang contributed equally to this work

1 Beijing Key Laboratory of Translational Medicine On Liver Cirrhosis, Liver

Research Center, Beijing Friendship Hospital, Capital Medical University,

95 Yong-An Road, Beijing 100050, China

Full list of author information is available at the end of the article
}

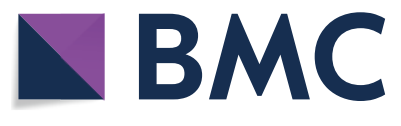

2021. Open Access This article is licensed under a Creative Commons Attribution 4.0 International License, which permits use, sharing, adaptation, distribution and reproduction in any medium or format, as long as you give appropriate credit to the original author(s) and the source, provide a link to the Creative Commons licence, and indicate if changes were made. The images or other third party material in this article are included in the article's Creative Commons licence, unless indicated otherwise in a credit line to the material. If material is not included in the article's Creative Commons licence and your intended use is not permitted by statutory regulation or exceeds the permitted use, you will need to obtain permission directly from the copyright holder. To view a copy of this licence, visit http://creativecommons.org/licenses/by/4.0/. The Creative Commons Public Domain Dedication waiver (http://creativecommons.org/publicdomain/zero/1.0/) applies to the data made available in this article, unless otherwise stated in a credit line to the data. 
Conclusions: This is the first comprehensive analysis about the gene variant spectrum and phenotypic aspects of non-HFE HH in China. The results will be useful to the identification, diagnosis and management of $\mathrm{HH}$ in China.

Keywords: Hereditary haemochromatosis $(H H)$, Non-HFE, Genotype, Genotype-phenotype

\section{Introduction}

Hereditary haemochromatosis $(\mathrm{HH})$ is an iron-storage disease, caused by mutations in genes involved of the regulation of iron homeostasis, resulting in excessive absorption and toxic accumulation of iron in the liver, pancreas, skin, heart, joints, and anterior pituitary gland [1]. In untreated individuals, iron overload can lead to liver fibrosis/cirrhosis, diabetes, skin pigmentation, heart disease, bone and joint disease, and hypogonadism. Hereditary hemochromatosis is associated with malignancies, particularly hepatocellular carcinoma [2]. Early recognition, diagnosis and treatment for hemochromatosis can reduce iron deposition and prevent disease progression [3, 4].

There are 4 main types of $\mathrm{HH}$ that have been categorized based on which proteins involved in iron homeostasis are affected [5]. Type $1 \mathrm{HH}$ is the most common form of $\mathrm{HH}$ in Caucasian populations, which is caused by homozygous p. C282Y or compound heterozygous p.C282Y/H63D mutations in HFE gene [6]. Type 2A, type $2 \mathrm{~B}$, type 3 , and type 4 are associated with pathogenic defects in the hemojuvelin (HJV), hepcidin (HAMP), transferrin receptor 2 (TFR2) and ferroportin (SLC4OA1) genes, respectively [7]. Mutations in the $H F E, H J V$, HAMP and TFR2 genes result in an autosomal recessive form of $\mathrm{HH}$, whereas mutation in the $S L C 40 A 1$ gene results in an autosomal dominant form of $\mathrm{HH}$ [7].

The majority of $\mathrm{HH}$ cases are related to non-HFE genes in Asian countries [8,9]. In addition, some novel gene variants related to the regulation of iron homeostasis have been identified in Chinese $\mathrm{HH}$ patients. In our previous study, SUGP2 p. R639Q, BMP4 p. R269Q, and $D E N N D 3$ p. L708V were first identified in $\mathrm{HH}$ patients [10].

However, less is known about the clinical features and genetic correlation of non- $H F E \mathrm{HH}$ in Asian populations. Therefore, in the present study, we investigated the genetic characteristics and relationship between genotype and phenotype of non- HFE $\mathrm{HH}$ in a cohort of patients with $\mathrm{HH}$ in China.

\section{Methods \\ Patients}

Patients with iron overload were enrolled from the China Registry of Genetic/Metabolic Liver Diseases (CR-GMLD, Clinical trials. gov: NCT03131427) since October 2014. This study was approved by the Clinical
Research Ethics Committee of Beijing Friendship Hospital, Capital Medical University (No. 2016-P2-061-01). Informed and written consent was obtained for the study from all patients.

The inclusion criteria were based on the American Association for the Study of Liver Diseases 2011 practice guidelines on hemochromatosis [6, 11]: (1) elevated ferritin $(>300 \mathrm{ng} / \mathrm{mL}$ in men and postmenopausal women or $>200 \mathrm{ng} / \mathrm{mL}$ in premenopausal women) and/or transferrin saturation (TS) $\geq 45 \%$; (2) iron overload in the liver and/or spleen on magnetic resonance imaging (MRI) of the liver or liver histology.

The exclusion criteria: (1) alcoholic liver disease, chronic hepatitis $\mathrm{B}$ or $\mathrm{C}$, or other chronic liver disease; (2) iron-overloading anemia; (3) parenteral iron overload.

\section{Clinical and laboratory profiles}

The following information were included in the studies: Sex; Age at diagnosis; laboratory data: serum ferritin (SF, a surrogate marker of storage iron), transferrin saturation (TS, the ratio of iron on transferrin); liver chemistry including ALT, AST, GGT, TBIL and ALB; clinical features at presentation: (a) liver fibrosis or cirrhosis, (b) skin pigmentation, (c) arthritis or arthropathy, (d) cardiac involvement (including cardiomyopathy), (e) diabetes or hyperglycemia, (f) hypogonadism.

\section{Screening for gene variants}

Genomic DNA was extracted from whole blood using a Genomic DNA Purification Kit (Qiagen, Valencia, CA). All exons of known HH related genes (HFE, HJV, HAMP, TFR2 and SLC4OA1) and exons with mutations in the novel iron homeostasis-related genes (DENND3 p.L708V and SUGP2 p.R639Q), were PCR-amplified with their associated boundary regions using primers described in our previous studies [10].

PCR amplification was performed in an ABI Veriti 96 PCR cycler (Applied Biosystems, MA, USA). PCR products were sequenced in forward and reverse orientations using an automated ABI 3730 DNA sequencer (Applied Biosystems). Three predictors, Polyphen-2 (http://genet ics.bwh.harvard.edu), SIFT (http://sift.jcvi.org/) and Mutation Taster (http://www.mutationtaster.org/), were used to predict the functional consequence of the identified variants.

We defined pathogenic or likely pathogenic variants as those variants meeting one of the following criteria 
[12-14]: (1) the variants had previously been reported in the literature; (2) the variants were present in the HGMD, dbSNP, and ClinVar databases; (3) functional effect predictors predicted to be "damaging" by at least two of the three prediction tools were considered to be pathogenic variants; (4) the terms were used by standards and guidelines for the interpretation of sequence variants.

\section{Statistical analysis}

We used SPSS software V.26.0 to conduct all statistical comparisons. Continuous variables were presented as the mean \pm standard deviation and compared using one-way ANOVA and LSD-t test, while continuous non-parametric variables were presented as median \pm interquartile range and compared using Kruskal-Wallis ANOVA test. Discontinuous variables were compared using chi-square test and Fisher's exact test. $p$ Values of less than 0.05 was considered to be statistically significant.

\section{Results}

\section{Clinical profiles of the enrolled patients}

Thirty-two patients with primary iron overload from the CR-GMLD were recruited to screen for genetic variants in known HH-related genes and novel iron homeostasis-related genes. All the probands with primary iron overload were validated by liver biopsy and/or MRI examinations. Demographic characteristics of patients with non-HFE HH are shown in Table 1.

\section{Gene variants distribution}

We found that genetic variants forms of Chinese patients with primary iron overload are mainly non-HFE-related combined heterozygous variants. 1 case $(3.13 \%)$ carried combined heterozygous $H F E$ p.C282Y/71X pathogenic variants. 8 cases $(25 \%)$ carried $H J V$ pathogenic variants, among which 4 cases carried homozygous pathogenic variants in $H J V$ gene, including p. Q6H, p. F103L, p. Q312X and p. C321X. 7 (21.88\%) cases with SLC4OA1 pathogenic variants, $8(25 \%)$ cases with SUGP2 likely pathogenic variants, $5(15.63 \%)$ cases with DENND3 likely pathogenic variants. None of damaging or probably damaging variants for HAMP and TFR2 was identified in any cases. Representative predicted pathogenic variants and allele frequency of $\mathrm{HH}$ included in this study are shown in Table 2. Representative pedigree analysis of four families are shown in Fig. 1.

Among these 31 non-HFE HH cases, 4 cases harbored homozygous variants, 2 cases harbored homozygous + heterozygous variants, 19 cases harbored heterozygous or combined heterozygous variants, and 6 cases harbored no damaging variants. Genetic characteristics of patients with $\mathrm{HH}$ are shown in Table 3.

Table 1 Demographic characteristics of patients in in different groups with $\mathrm{HH}$

\begin{tabular}{|c|c|c|c|c|c|c|}
\hline Characteristic & Total (32) & HJV $(n=8)$ & $\operatorname{SLC40A1}(n=6)$ & SUGP2 or DENND3 $(n=10)$ & $\begin{array}{l}\text { HH without } P \\
\text { or LP variants* } \\
(n=6)\end{array}$ & $p$ \\
\hline Male, n (\%) & 23(71.9) & $6(75)$ & $4(66.7)$ & $8(80)$ & $4(66.7)$ & 0.897 \\
\hline Age, y & $45.07 \pm 15.94(18-79)$ & $30.13 \pm 12.12$ & $56.33 \pm 6.83^{\mathrm{a}}$ & $48.30 \pm 16.99^{a}$ & $48.33 \pm 12.55^{\mathrm{a}}$ & 0.007 \\
\hline $\mathrm{SF}, \mathrm{ng} / \mathrm{ml}$ & $2631.0(1115.95,6371.25)$ & $6153(3246.5,6922.5)$ & $\begin{array}{l}5917.6 \\
(2061.8,9333.8)\end{array}$ & $972^{\mathrm{ab}}(670.3,2467.1)$ & $\begin{array}{l}1267 \\
(1033.8,10129.7)\end{array}$ & 0.010 \\
\hline $\mathrm{TS}, \%$ & $92.30(81.30,96.10)$ & $\begin{array}{l}94.85 \\
(92.25,97.5)\end{array}$ & $\begin{array}{l}92.25 \\
(60.43,95.75)\end{array}$ & $85.0(58.5,96.7)$ & $88.35(70.6,93.5)$ & 0.210 \\
\hline$A L T, U / L$ & $72.0(30.0,104.0)$ & $99.5(67.3,12)$ & $78.5(39.5,141.3)$ & $31(22.5,44.5)$ & $72(18.5,121.5)$ & 0.161 \\
\hline AST, U/L & $62.8(34.6,103.0)$ & $92(64.4,121.0)$ & $60.4(37.6,111.8)$ & $33.4(22.9,48.5)$ & $72(20.7,124.3)$ & 0.051 \\
\hline GGT, U/L & $42(27.00,72.0)$ & $48(34.3,75)$ & $38(19.8,278.3)$ & $29.9(26.5,58.5)$ & $56(22.5,403)$ & 0.622 \\
\hline TBIL, $\mu \mathrm{mol} / \mathrm{L}$ & $37.88 \pm 43.86$ & $17.56 \pm 8.85$ & $18.79 \pm 10.72$ & $64.14 \pm 62.59^{a}$ & $51.25 \pm 48.90$ & 0.094 \\
\hline$A L B, g / L$ & $40.30 \pm 8.33$ & $43.98 \pm 10.12$ & $38.88 \pm 3.87$ & $39.14 \pm 9.42$ & $37.96 \pm 7.58$ & 0.540 \\
\hline Cirrhosis & 11 & 0 & 5 & 4 & 2 & 0.011 \\
\hline Skin pigmentation & 13 & 4 & 4 & 2 & 3 & 0.281 \\
\hline Arthropathy & 2 & 1 & 1 & 0 & 0 & 0.540 \\
\hline Cardiac involvement & 5 & 3 & 0 & 0 & 2 & 0.042 \\
\hline Diabetes & 11 & 3 & 5 & 1 & 2 & 0.035 \\
\hline Hypogonadism & 9 & 5 & 3 & 1 & 0 & 0.020 \\
\hline
\end{tabular}

$\mathrm{HH}$ without $\mathrm{P}$ or $\mathrm{LP}$ variants ${ }^{*}=\mathrm{HH}$ without pathogenic or likely pathogenic variants, $\mathrm{SF}=$ serum ferritin,

$\mathrm{TS}=$ transferrin saturation, $\mathrm{ALT}=$ alanine transaminase, $\mathrm{AST}=$ aspartate aminotransferase,

GGT $=\gamma$-glutamyltransferase, $\mathrm{TBIL}=$ total bilirubin, $\mathrm{ALB}=$ albumin; Statistically significant differences are denoted as (a) compared to HJV. Statistically significant differences are denoted as (b) compared to SLC40A1 


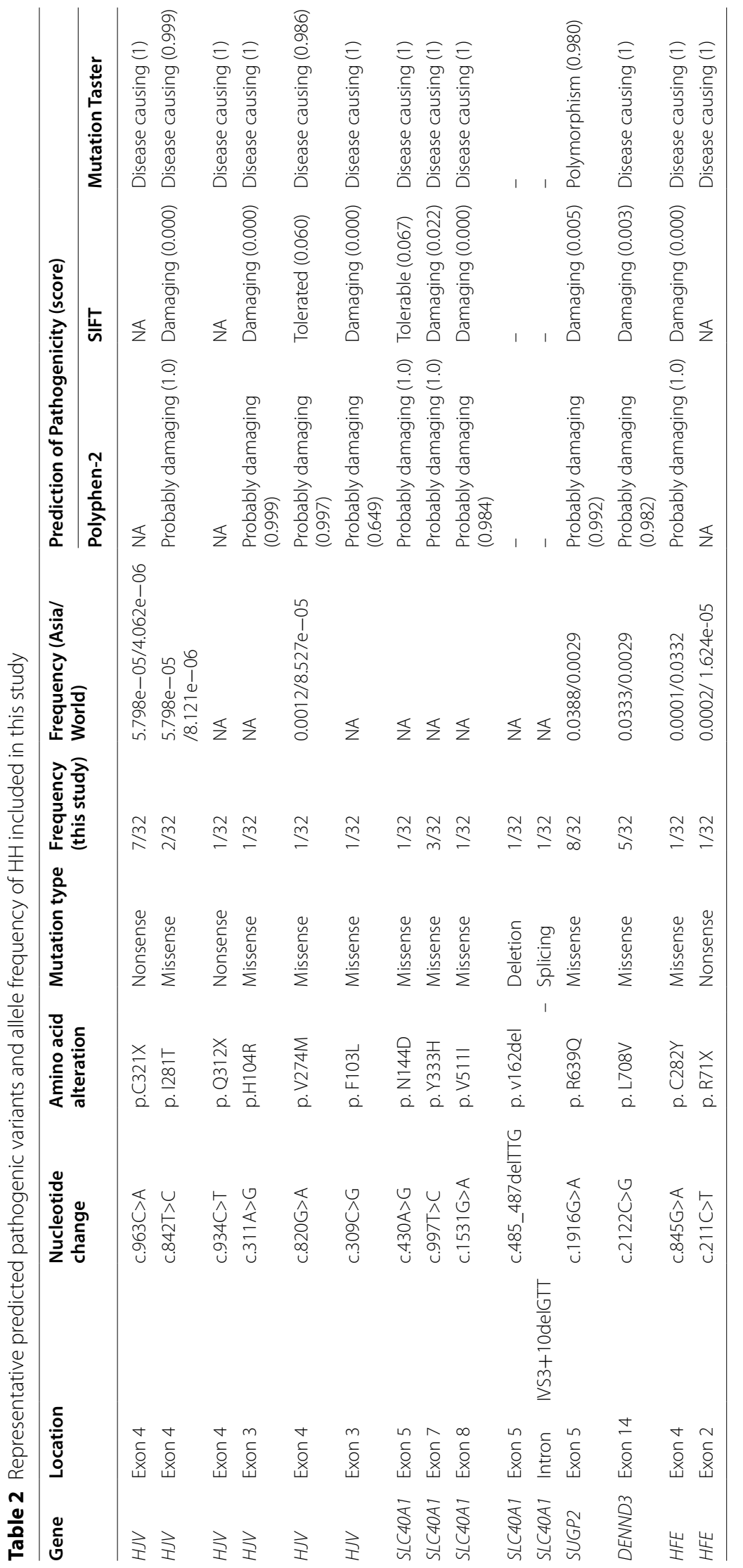


A

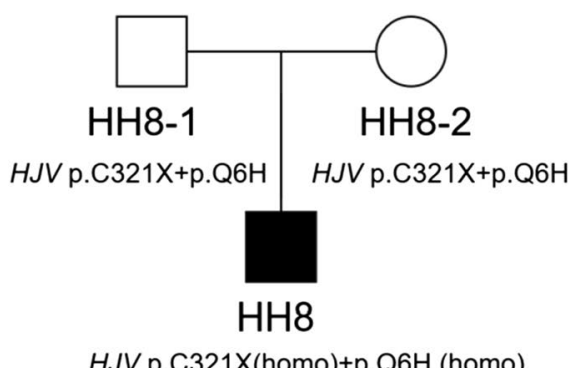

$\mathrm{C}$

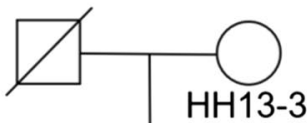

SLC4OA1 P.Y $333 \mathrm{H}$

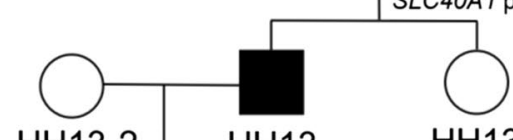

HH13-2 HH13 HH13-4

TFR2 p. I238M SLC40A1 p.Y333H SLC4OA1 p.Y333H

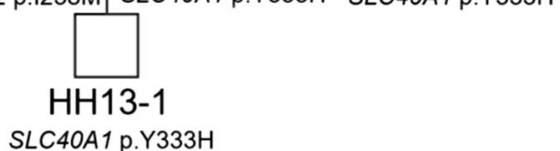

B

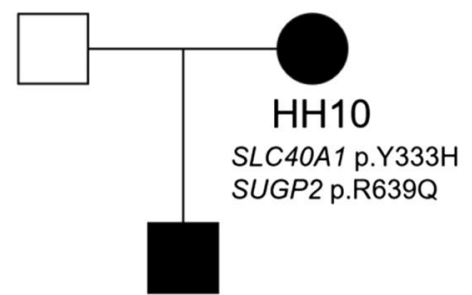

$\mathrm{HH} 10-1$

SLC4OA1 p.Y333H

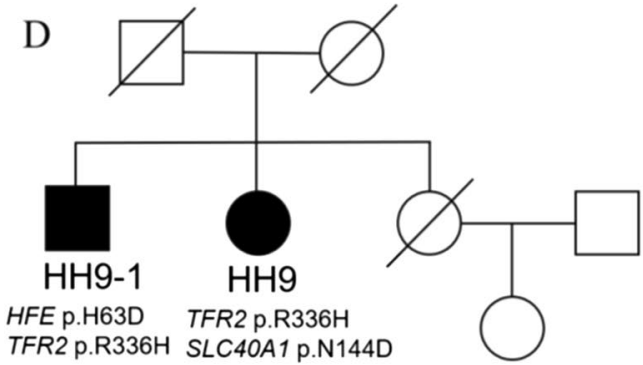

$\mathrm{HH}$-2

HFE p.H63D

SLC40A1 p.N144D

Fig. 1 Representative pedigree analysis of four families. A Pedigree chart of family HH8. The patient (HH8) harbored homozygous variations of HJV p.C321X and HJV p.Q6H, which were inherited from their father and mother. B Pedigree chart of family HH10. The patient (HH10) harbored compound heterozygous variations of SLC40A1 p.Y333H and SUGP2 p.R639Q. C Pedigree chart of family HH13. The patient (HH13) harbored a single heterozygous variation of SLC4OA1 p.Y333H, which was inherited from their mother. D Pedigree chart of family HH9. The patient (HH9) harbored compound heterozygous variations of SLC40A1 p.N144D and TFR2 p.R336H

\section{Grouping of non-HFE HH}

Patients with non-HFE related $\mathrm{HH}$ were divided into four groups in the study, HJV HH (Type 2A HH), SLC4OA1 $\mathrm{HH}$ (Type 4B HH), SUGP2 or DENND3 variants $\mathrm{HH}$ and No pathogenic or likely pathogenic variants $\mathrm{HH}$ groups, based on the pathogenic variants identified in these cases. Demographic and laboratory characteristics of the four groups of $\mathrm{HH}$ cases are shown in Table 1.

Among the 31 cases with non-HFE related $\mathrm{HH}, 2$ cases (the first is SLC40A1 p. Y333H+SUGP2 p. R639Q, the second is SLC4OA1 IVS3+10delGTT+SUGP2 p. R639Q(homo)) carried two different pathogenic or likely pathogenic variants. The first was grouped into the SLC4OA1 HH due to the definite pathogenicity of SLC4OA1 p. Y333H. Previous functional studies showed that the $S L C 40 A 1$ p. Y333H variant was associated with gain-of-function of ferroportin and caused iron overload and organ damage [15]. The second carried two likely pathogenic variants. This patient was a 48-year-old female with SF $7078 \mathrm{ng} / \mathrm{ml}$ and TS 99.7\%. Liver biopsy suggested that iron deposition was predominant in hepatocytes, MRI suggested iron overload in liver and spleen, and gene test suggested SLC4OA1 IVS3 + 10delGTT + SUGP2 p. R639Q(homo) combined likely pathogenic variants. We excluded this patient due to difficulty in grouping. Therefore, we finally analyzed the remaining 30 cases.

\section{Genotype and phenotype associations in different types of non-HFE HH HJV HH (Type 2A HH)}

There were more males than females in $H J V \mathrm{HH}$, the ratio of males and females was 3:1. Mean age at diagnosis of this group of patients was the lowest (30 years) in the four types. Totally, $62.5 \%$ of the patients had hypogonadism, half of them developed skin pigmentation, $37.5 \%$ had both cardiac involvement and diabetes. Only one case developed arthropathy. None of patients in $H J V$ $\mathrm{HH}$ developed cirrhosis.

ALT and AST (median 99.5 and $92 \mathrm{U} / \mathrm{L}$ ) levels increased in this group. GGT (median $48 \mathrm{U} / \mathrm{L}$ ), TBIL (mean $17.6 \mu \mathrm{mol} / \mathrm{L}$ ) and ALB (mean $44.0 \mathrm{~g} / \mathrm{L}$ ) levels were normal. The median SF $(6153 \mathrm{ng} / \mathrm{ml})$ and TS (median 95\%) levels were highest in four types.

\section{SLC40A1 HH (Type 4B HH)}

There were more males than females in SLC4OA1 HH, the ratio of males and females was 2:1. Mean age at diagnosis 
Table 3 Genetic characteristics of 32 patients in $\mathrm{HH}$ cases

\begin{tabular}{|c|c|c|c|c|c|c|c|c|}
\hline NO & Age & Gender & $\mathrm{SF}(\mathrm{ng} / \mathrm{ml})$ & TS (\%) & $\begin{array}{l}\text { Iron deposition on liver } \\
\text { biopsy }\end{array}$ & Iron overload on MRI & Known HH-related genes & $\begin{array}{l}\text { Iron homeostasis -related } \\
\text { genes }\end{array}$ \\
\hline 1 & 26 & M & 7004 & 92.0 & $\begin{array}{l}\text { Predominant in hepato- } \\
\text { cytes }\end{array}$ & Liver & HJV p.Q6H/C321X/I281T & - \\
\hline 2 & 28 & M & 6269 & 95.4 & $\begin{array}{l}\text { Predominant in hepato- } \\
\text { cytes }\end{array}$ & Liver, pancreas & HJV p.Q6H/C321X/I281T & - \\
\hline 3 & 22 & $\mathrm{~F}$ & 2995 & 89.1 & $\begin{array}{l}\text { Predominant in hepato- } \\
\text { cytes }\end{array}$ & Liver, pancreas & HJV p. Q312X (homo) & - \\
\hline 4 & 18 & M & 6678 & 100 & $\begin{array}{l}\text { Predominant in hepato- } \\
\text { cytes }\end{array}$ & ND & HJV p.Q6H/C321X/H104R & - \\
\hline 5 & 57 & M & 4001 & 93.0 & $\begin{array}{l}\text { Predominant in hepato- } \\
\text { cytes }\end{array}$ & Liver & HJV p.Q6H/C321X/V274M & - \\
\hline 6 & 36 & $\mathrm{~F}$ & 2000 & 96.0 & $\begin{array}{l}\text { Predominant in hepato- } \\
\text { cytes }\end{array}$ & Liver & HJV p. F103L (homo) & - \\
\hline 7 & 30 & M & 11,555 & 98.0 & ND & Liver, spleen, pancreas & $\begin{array}{l}\text { HJV p. Q6H(homo)/ C321X } \\
\text { (homo) }\end{array}$ & - \\
\hline 8 & 24 & M & 6037 & 94.3 & ND & Liver, pancreas & $\begin{array}{l}\text { HJV p. Q6H(homo)/C321X } \\
\text { (homo) }\end{array}$ & - \\
\hline 9 & 57 & $\mathrm{~F}$ & 5886.1 & 71.1 & $\begin{array}{l}\text { Hepatocytes and reticu- } \\
\text { loendothelial cells }\end{array}$ & Liver, spleen, pancreas & SLC40A1 p. N144D & - \\
\hline 10 & 66 & $\mathrm{~F}$ & 1446.2 & 92.7 & ND & Liver, spleen, pancreas & SLC40A1 p. Y333H & SUGP2 p. R639Q \\
\hline 11 & 48 & M & $2267-$ & 91.8 & ND & Liver, spleen, pancreas & SLC40A1 p.V511। & - \\
\hline 12 & 58 & M & 5949 & 28.4 & $\begin{array}{l}\text { Predominant in hepato- } \\
\text { cytes }\end{array}$ & Liver, spleen & SLC40A1 p. v162del & - \\
\hline 13 & 49 & M & 7445 & 97.0 & $\begin{array}{l}\text { Predominant in hepato- } \\
\text { cytes }\end{array}$ & Liver, spleen & SLC40A1 p. Y333H & - \\
\hline 14 & 60 & M & 15,000 & 94.0 & $\begin{array}{l}\text { Predominant in hepato- } \\
\text { cytes }\end{array}$ & Liver, spleen, pancreas & SLC40A1 p. Y333H & - \\
\hline 15 & 79 & M & 493.8 & $97.1-$ & ND & Liver, pancreas & - & SUGP2 p. R639Q \\
\hline 16 & 63 & M & 3868 & 97.7 & $\begin{array}{l}\text { Predominant in hepato- } \\
\text { cytes }\end{array}$ & Liver, spleen & - & SUGP2 p. R639Q \\
\hline 17 & 67 & M & 1102 & 92.3 & $\begin{array}{l}\text { Predominant in hepato- } \\
\text { cytes }\end{array}$ & Liver, spleen & - & $\begin{array}{l}\text { DENND3 p. L708V(homo) } \\
\text { SUGP2 p. R639Q }\end{array}$ \\
\hline 18 & 28 & M & 738 & 46.4 & $\begin{array}{l}\text { Predominant in hepato- } \\
\text { cytes }\end{array}$ & ND & - & DENND3 p. L708V \\
\hline 19 & 38 & $\mathrm{~F}$ & 843 & 96.2 & $\begin{array}{l}\text { Predominant in hepato- } \\
\text { cytes }\end{array}$ & ND & - & DENND3 p. L708V \\
\hline 20 & 53 & $\mathrm{~F}$ & 1402 & 49.0 & $\begin{array}{l}\text { Predominant in hepato- } \\
\text { cytes }\end{array}$ & Liver, spleen & - & SUGP2 p. R639Q \\
\hline 21 & 46 & M & 2000 & 85.0 & ND & Liver, spleen & - & SUGP2 p. R639Q \\
\hline 22 & 45 & M & 685 & - & $\begin{array}{l}\text { Predominant in hepato- } \\
\text { cytes }\end{array}$ & ND & - & DENND3 p. L708V \\
\hline 23 & 33 & M & 626 & 68.0 & $\begin{array}{l}\text { Hepatocytes and reticu- } \\
\text { loendothelial cells }\end{array}$ & ND & - & SUGP2 p. R639Q \\
\hline 24 & 31 & M & 6000 & 81.0 & ND & Liver & - & DENND3 p. L708V \\
\hline 25 & 66 & $\mathrm{~F}$ & $12,703-$ & 91.7 & $\begin{array}{l}\text { Predominant in hepato- } \\
\text { cytes }\end{array}$ & Liver, spleen, pancreas & - & - \\
\hline 26 & 50 & $\mathrm{~F}$ & 9272 & 81.6 & $\begin{array}{l}\text { Predominant in hepato- } \\
\text { cytes }\end{array}$ & Liver, spleen, pancreas & - & - \\
\hline 27 & 53 & M & 1121 & 37.6 & $\begin{array}{l}\text { Predominant in reticuloen- } \\
\text { dothelial cells }\end{array}$ & Liver, spleen & - & - \\
\hline 28 & 53 & M & 773 & 96.8 & $\begin{array}{l}\text { Predominant in hepato- } \\
\text { cytes }\end{array}$ & Liver & - & - \\
\hline 29 & 31 & M & 1220 & 92.4 & ND & Liver, spleen, pancreas & - & - \\
\hline 30 & 37 & M & 1316 & 85.0 & ND & Liver, spleen & - & - \\
\hline 31 & 48 & $\mathrm{~F}$ & 7078 & 99.7 & $\begin{array}{l}\text { Predominant in hepato- } \\
\text { cytes }\end{array}$ & Liver, spleen & SLC40A1 IVS3 + 10delGTT & SUGP2 p. R639Q(homo) \\
\hline 32 & 28 & M & 2153 & 91.7 & $\begin{array}{l}\text { Predominant in hepato- } \\
\text { cytes }\end{array}$ & Liver & HFE p.C282Y/R71X & - \\
\hline
\end{tabular}


Table 3 (continued)

of this group of patients was the highest (56 years) in the four types. Totally, $83.3 \%$ of the patients had both cirrhosis and diabetes, $66.6 \%$ had skin pigmentation, half of them had hypogonadism. Only one case had arthropathy. None of patients in SLC4OA1 HH developed cardiac diseases.

ALT and AST (median 78.5 and $60.4 \mathrm{U} / \mathrm{L}$ ) levels increased in this group. GGT (median $38 \mathrm{U} / \mathrm{L}$ ), TBIL (mean $18.9 \mu \mathrm{mol} / \mathrm{L}$ ), and ALB (mean $38.9 \mathrm{~g} / \mathrm{L}$ ) levels were normal. The median SF level was $5918 \mathrm{ng} / \mathrm{ml}$. The median TS was $92 \%$.

\section{SUGP2 or DENND3 variants HH}

There were more males than females in SUGP2 or DENND3 $\mathrm{HH}$, the ratio of males and females was $4: 1$. Mean age at diagnosis of this group of patients was 48 years. Totally, $40 \%$ of the patients had cirrhosis, $20 \%$ had skin pigmentation, $10 \%$ had both diabetes and hypogonadism. None of patients in SUGP2 or DENND3 HH developed arthropathy and cardiac diseases.

ALT (median $31 \mathrm{U} / \mathrm{L}$ ), AST (median 33.4 U/L), GGT (median $29.9 \mathrm{U} / \mathrm{L}$ ), and ALB (mean $39.1 \mathrm{~g} / \mathrm{L}$ ) levels were normal in this group. TBIL (mean $64.1 \mu \mathrm{mol} / \mathrm{L}$ ) levels were higher than other groups. The median SF level was $972 \mathrm{ng} / \mathrm{ml}$. The median TS level was $85 \%$.

\section{HH without pathogenic or likely pathogenic variants}

There were more males than females in $\mathrm{HH}$ without pathogenic or likely pathogenic variants, the ratio of males and females was 2:1. Mean age at diagnosis of this group of patients was 48 years. Totally, $50 \%$ of the patients had skin pigmentation, $33.3 \%$ had cirrhosis, $33.3 \%$ had both cardiac diseases and diabetes. None of patients developed arthropathy and hypogonadism.

ALT and AST (median 72 and $72 \mathrm{U} / \mathrm{L}$ ), TBIL (mean $51.3 \mu \mathrm{mol} / \mathrm{L}$ ) levels increased in this group. GGT (median $56 \mathrm{U} / \mathrm{L}$ ) and ALB (mean $38.0 \mathrm{~g} / \mathrm{L}$ ) levels were normal. The median SF level was $1267 \mathrm{ng} / \mathrm{ml}$. The median TS level was $88 \%$.

There were more males than females in all groups (Fig. 2A). The age at diagnosis was statistically different between $H J V \mathrm{HH}$ and SLC4OA1 $\mathrm{HH}$ groups $(\mathrm{p}=0.001)$, between HJV HH and SUGP2 or DENND3 $\mathrm{HH}$ groups $(p=0.008)$, between $H J V \mathrm{HH}$ and $\mathrm{HH}$ without pathogenic or likely pathogenic variants groups $(p=0.018)$, while the comparison between other groups was not statistically significant (Fig. 2B). The incidence of cirrhosis $(p=0.011)$, cardiac involvement $(p=0.042)$, diabetes $(p=0.035)$ and hypogonadism $(p=0.020)$ was statistically significant in the four groups. However, due to the limited sample size, the pairwise comparison showed no significant difference (Fig. 3). HH without P or LP
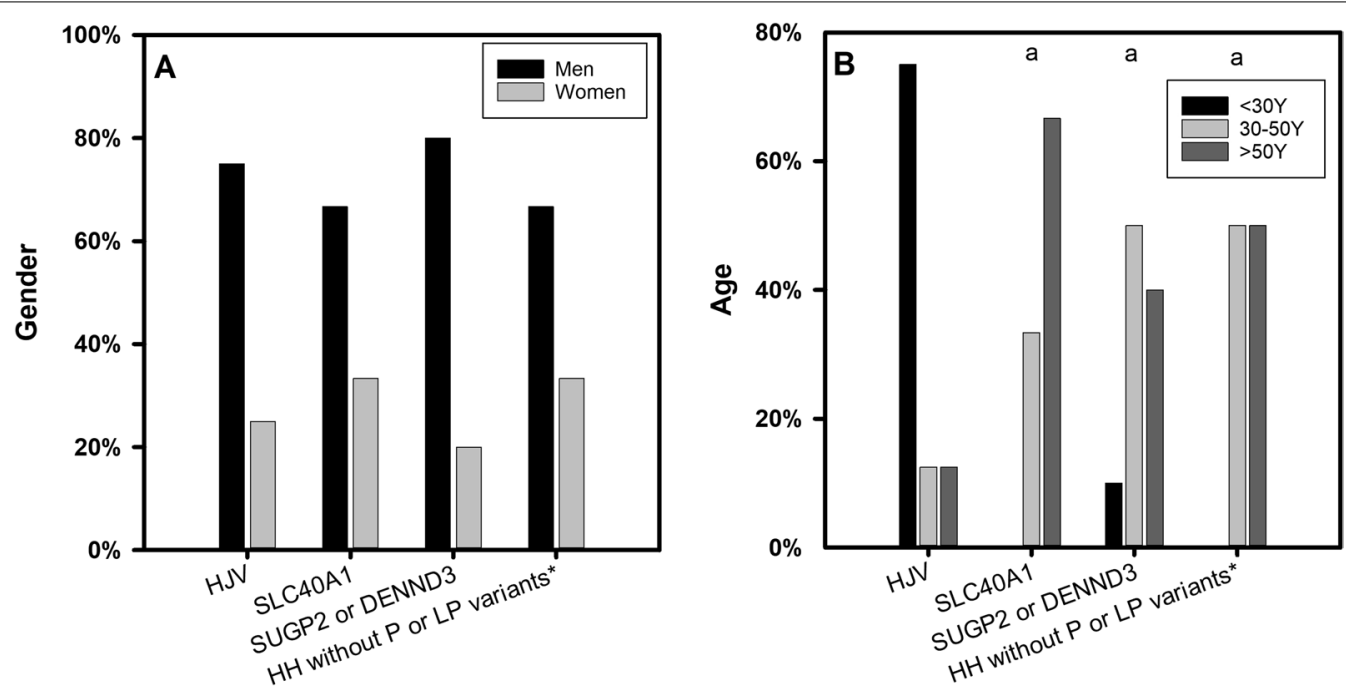

Fig. 2 Gender and age at diagnosis of patients with non-HFE-related HH. A Gender and B Age at diagnosis are shown for patients with HJV HH, SLC4OA1 HH, SUGP2 or DENND3 HH and HH without pathogenic or likely pathogenic variants. Graphs A show the ratios of males and females in the four groups. Variables were compared using chi-square test and Fisher's exact test. There are no statistical differences between the groups. Graphs B show percentage of patients at different age stages (<30Y, 30-50Y, > 50Y). Variables were compared using one-way ANOVA and LSD-t test. Statistically significant differences are denoted as (a) compared to HJV 

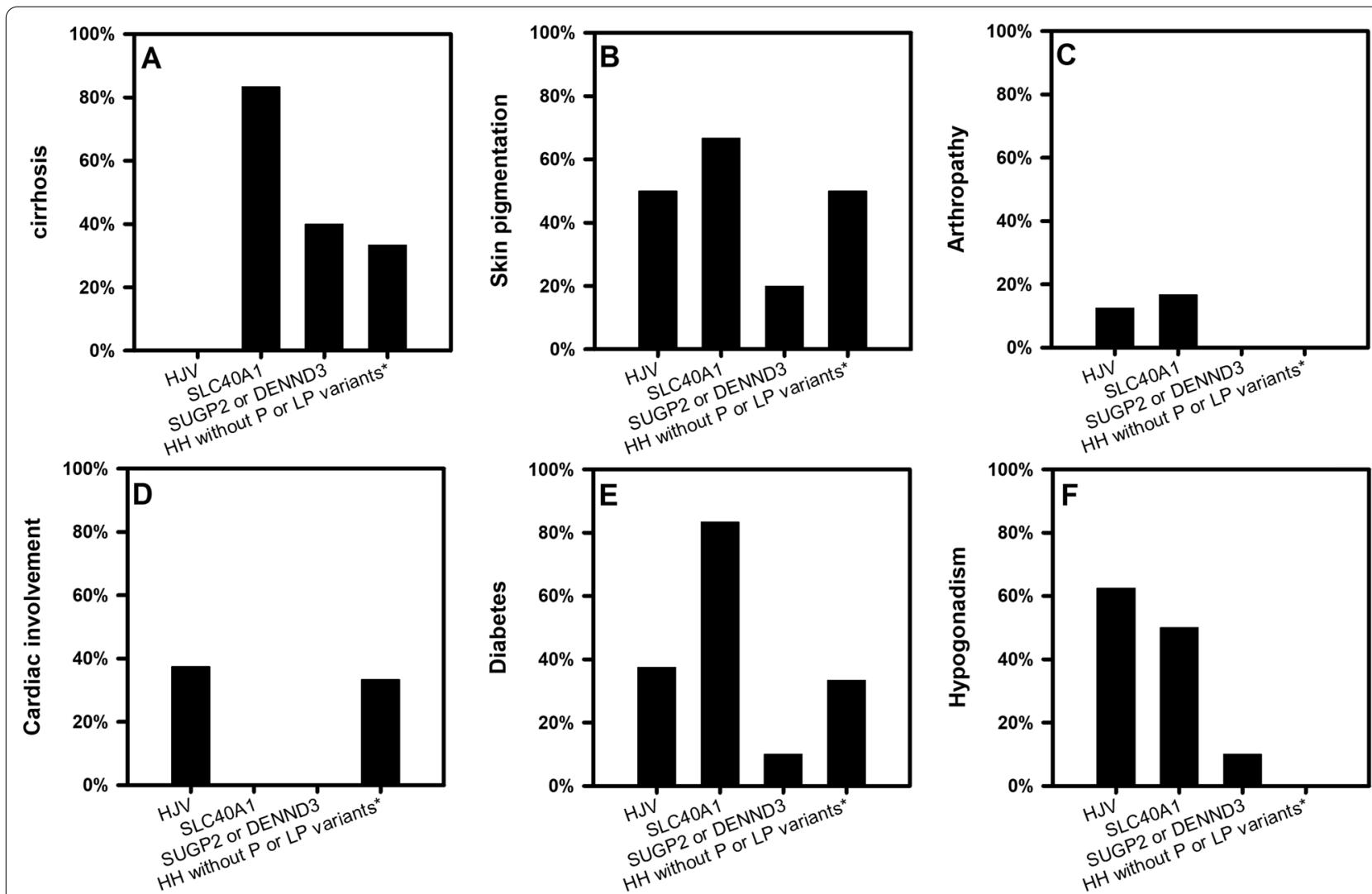

Fig. 3 Clinical characteristics at diagnosis of patients with non-HFE-related $\mathrm{HH}$. The presence or absence of clinical characteristics was determined in all patients with genetic diagnosis of HJV HH, SLC4OA1 HH, SUGP2 or DENND3 HH and HH without pathogenic or likely pathogenic variants. A Cirrhosis, B Skin pigmentation, C Arthropathy, D Cardiac involvement, E Diabetes and $\mathbf{F}$ Hypogonadism at diagnosis are shown for subjects in the four groups. Variables were compared using chi-square test and Fisher's exact test. Differences in clinical characteristics with Cirrhosis, Cardiac involvement, Hypogonadism were statistically significant in the four groups. However, due to the limited sample size, the pairwise comparison showed no significant difference

variants $^{*}=\mathrm{HH}$ without pathogenic or likely pathogenic variants.

TBIL levels were significantly higher in SUGP2 or DENND3 $\mathrm{HH}$ when compared to $H J V \mathrm{HH}$ groups $(p=0.032)$. There was no significant difference about other liver function indices in the four groups. SF levels increased greatly in all the four groups. There were statistical differences between $H J V \mathrm{HH}$ and SUGP2 or DENND3 HH groups $(p=0.002)$, between SLC4OA1 HH and SUGP2 or DENND3 HH groups $(p=0.01)$, while the comparison between other groups was not statistically significant. TS increased greatly in all $\mathrm{HH}$ groups, with a median TS of $92 \%$ in all cases.

\section{Discussion}

The present study demonstrated that the pathogenic gene of $\mathrm{HH}$ in China was mainly non-HFE genes, which is different from that in Caucasians. We only found one case carried combined heterozygous HFE p.C282Y/71X pathogenic variant in our study, which has been reported in our previous study [16]. The remaining 31 cases are non$H F E$-related $\mathrm{HH}$, especially in $H J V$ and SLC4OA1 genes. This suggests that type $2 \mathrm{~A} \mathrm{HH}$ and type $4 \mathrm{HH}$ are major forms of $\mathrm{HH}$ in Chinese populations. Also, we analyzed the correlation of the genotype and clinical phenotype of these $\mathrm{HH}$ patients.

In the present study, cases with $H J V$-related $\mathrm{HH}$ had an earlier age at diagnosis and more severe iron load. In contrast, SLC4OA1 HH, SUGP2 or DENND3 $\mathrm{HH}$ and $\mathrm{HH}$ without pathogenic or likely pathogenic variants occur relatively late, rarely before the age of 30 . Furthermore, most of the patients with $H J V \mathrm{HH}$ had heart failure as the first symptom, whereas there was no cirrhosis in $H J V$ $\mathrm{HH}$. A meta-analysis showed that cardiomyopathy is generally seen in individuals with much greater degrees of iron overload [17]. This is in line with the previous report that a much earlier and more serious deposition of iron in the heart in $H J V \mathrm{HH}$ [18]. However, the exact mechanism for the severer heart disease than the liver disease in $H J V \mathrm{HH}$ is still not clear. 
We also found cases with SLC40A1 HH had higher prevalence of cirrhosis and diabetes in this studies, which may be related to the severe iron overload and the late onset age of SLC4OA1 HH. Firstly, higher ferritin levels are independently associated with prevalent diabetes [19]. Some studies showed that increased ferritin was associated with increased risk of type 2 diabetes after adjustment for conventional risk factors for diabetes [20]. This relationship between iron and diabetes was also found in gestational diabetes and prediabetes $[21,22]$. Secondly, age is known to be a risk factor for diabetes. The older age may increase the more chances of developing cirrhosis and diabetes than $H J V \mathrm{HH}$. In addition, severe iron overload in pancreas was observed in some patients, which may be associated with the onset of diabetes.

In our previous study, function study showed that silencing SUGP2 expression downregulated the level of HAMP expression, and a decrease in the level of p-SMAD1/5 and TFR2 was observed in the Huh-7 cell line transfected with the DENND3 and DENND3 $\mathrm{p}$. L708V constructs [10]. In the present study, cases with SUGP2 or DENND3 HH group showed lower involvement of skin pigmentation, arthropathy, cardiac diseases, diabetes and hypogonadism, when compared to $H J V \mathrm{HH}$ group; and lower prevalence of cirrhosis when compared to $S L C 40 A 1 \mathrm{HH}$ group. This may be due to the lower accumulation of iron in SUGP2 or DENND3 $\mathrm{HH}$ group than $H J V \mathrm{HH}$ group and SLC40A1 $\mathrm{HH}$ group. Therefore, we may infer that the pathogenicity of SUGP2 or DENND3 gene variants is weaker than those in $H J V$ or $S L C 4 O A 1$ gene.

It is worth noting that $\mathrm{HH}$ without pathogenic or likely pathogenic variations were identified in 6 cases, suggesting that pathogenic variants may exist in other $\mathrm{HH}$-related genes. The second-generation sequencing for those unexplained $\mathrm{HH}$ cases would be justified.

Overall, our data showed that there were more men than women among these patients with different nonHFE genotypes. Relevant studies have found that the onset age of female patients is usually later than that of male patients [23]. The prevalence of high serum ferritin levels is higher in males than in females. We think the appearance of symptoms may also be associated to other non-genetic factors, such as alcohol and high-fat diet, and it may explain the protective effect against hemochromatosis by the fact that menstruation delay iron accumulation in women [23]. We found that in the $H J V \mathrm{HH}, S L C 4 O A 1 \mathrm{HH}$ and $\mathrm{HH}$ without pathogenic or likely pathogenic variants groups, about half of cases had skin pigmentation, whereas arthropathy occurred in only two cases. This is consistent with the previous reports that skin pigmentation is more prevalent and arthropathy is rare in non-HFE HH compared to HFE $\mathrm{HH}[18,24]$.

Studies have shown that there is significant positive correlations of SF with TS, ALT and AST [25]. The iron overload of type $2 \mathrm{~A}$ and type $4 \mathrm{HH}$ was higher than that of the other two groups. From the liver function tests in this study, ALT and AST increased in type 2A and type $4 \mathrm{HH}$. The rising trend of ALT/AST and SF in this study was consistent with the results of Barton J C [25].

Obviously, this study had some limitations. Firstly, the relatively small number of patients included preclude the conclusive correlation of genotype and phenotype. Secondly, we mainly focused on pathogenic or likely pathogenic variants and did not include the numerous combined heterozygous variants which might also confer various degree of pathogenicity. Thirdly, we did not analyze the histopathological characteristics, due to lack of liver biopsy in some patients.

\section{Conclusions}

In conclusion, this study suggested variants in non- $H F E$ genes were the main pathogenic genes in Chinese $\mathrm{HH}$ patients. Cases with $H J V$-related $\mathrm{HH}$ had an earlier age at diagnosis and the more severe iron load, whereas more cases with SLC4OA1 HH had cirrhosis and diabetes. SUGP2 and DENND3 were likely pathogenic variants for $\mathrm{HH}$ in China.

\section{Abbreviations}

HH: Hereditary hemochromatosis; HFE: Haemochromatosis; HJV: Hemojuvelin; HAMP: Hepcidin; TFR2: Transferrin receptor 2; SLC4OA1: Ferroportin; DENND3: DENN domain-containing protein 3; SUGP2: SURP and G patch domain containing 2; MRI: Magnetic resonance imaging; SF: Serum ferritin; TS: Transferrin saturation; ALT: Alanine transaminase; AST: Aspartate aminotransferase; GGT : $ү$-Glutamyltransferase; TBIL: Total bilirubin; ALB: Albumin; PCR: Polymerase chain reaction.

\section{Acknowledgements \\ We are grateful to the patients and their families for their supports and partici- pation in this study.}

\section{Authors' contributions}

LW and WZ contributed equally to this work. LW, WZ, XO and JH participated in the design of the study. LW, WZ, YL, DZ, BZ and AX performed the targeted Sanger sequencing, sequencing data analysis and prediction

of variants. LW, WZ, ZW, LW, SL, XW, XZ, QW, YW and HY performed recruitment of patients and collected clinical data. LW and ML did the statistical analysis. LW drafted the manuscript. LW helped to draft the manuscript. LW, $\mathrm{WZ}, \mathrm{JH}, \mathrm{XO}$ and $\mathrm{J} J$ revised it critically for intellectual content. All authors read and approved the final manuscript.

\section{Funding}

This work was supported by grants from the National Key Technologies R\&D Program of China (No. 2015BAl13B09), the National Natural Science Foundation of China (No. 82070598), the Youth Programme of Beijing Hospitals Authority (No. QML20190105), and the Digestive Medical Coordinated Development Center of Beijing Hospitals Authority (No. XXZ0502). 


\section{Availability of data and materials}

The datasets used and/or analyzed during the current study are available from the corresponding author on reasonable request.

\section{Declarations}

\section{Ethics approval and consent to participate}

This study was approved by the Clinical Research Ethics Committee of Beijing Friendship Hospital, Capital Medical University (No. 2016-P2-061-01). Informed and written consent was obtained for the study from all patients.

\section{Consent for publication}

All authors agreed on the manuscript.

\section{Competing interests}

The authors declare that they have no competing interests.

\begin{abstract}
Author details
${ }^{1}$ Beijing Key Laboratory of Translational Medicine On Liver Cirrhosis, Liver Research Center, Beijing Friendship Hospital, Capital Medical University, 95 Yong-An Road, Beijing 100050, China. ${ }^{2}$ National Clinical Research Center for Digestive Diseases, Beijing 100050, China. ${ }^{3}$ Liver Research Center, Experimental Center, Beijing Friendship Hospital, Capital Medical University, 95 Yong-An Road, Beijing 100050, China. ${ }^{4}$ Department of Clinical Epidemiology and EBM, National Clinical Research Center for Digestive Diseases, Beijing Friendship Hospital, Capital Medical University, Beijing 100050, China.
\end{abstract}

Received: 20 March 2021 Accepted: 20 September 2021 Published online: 28 September 2021

\section{References}

1. Pietrangelo A. Hereditary hemochromatosis: pathogenesis, diagnosis, and treatment. Gastroenterology. 2010;139(2):393-408.

2. Crownover BK, Covey CJ. Hereditary hemochromatosis. Am Fam Physician. 2013;87(3):183-90.

3. Pericleous $M$, Kelly $C$. The clinical management of hereditary haemochromatosis. Front Gastroenterol. 2017;9(2):110-4.

4. Adams PC, Speechley M, Kertesz AE. Long-term survival analysis in hereditary hemochromatosis. Gastroenterology. 1991;101(2):368-72.

5. Brissot P, Pietrangelo A, Adams PC, de Graaff B, McLaren CE, Loréal O. Haemochromatosis. Nat Rev Dis Primers. 2018;4:18016.

6. Bacon BR, Adams PC, Kowdley KV, Powell LW, Tavill AS; American Association for the Study of Liver Diseases. Diagnosis and Management of Hemochromatosis: 2011 Practice Guideline by the American Association for the Study of Liver Diseases. Hepatology. 2011;54(1): 328-343.

7. Pietrangelo A. Hereditary hemochromatosis-a new look at an old disease. N Engl J Med. 2004;350(23):2383-97.

8. McDonald CJ, Wallace DF, Crawford DH, Subramaniam VN. Iron storage disease in Asia-Pacific populations: the importance of non-HFE mutations. J Gastroenterol Hepatol. 2013;28(7):1087-94

9. Wang Y, Du Y, Liu G, Guo S, Hou B, Jiang X, et al. Identification of novel mutations in HFE, HFE2, TFR2, and SLC40A1 genes in Chinese patients affected by hereditary hemochromatosis. Int J Hematol. 2017;105(4):521-5.

10. Lv T, Zhang W, Xu A, Li Y, Zhou D, Zhang B, et al. Non-HFE mutations in haemochromatosis in China: combination of heterozygous mutations involving HJV signal peptide variants. J Med Genet. 2018;55(10):650-60.

11. Adams P, Altes A, Brissot P, Butzeck B, Cabantchik I, Cançado R, et al. Therapeutic recommendations in HFE hemochromatosis for p.Cys282Tyr (C282Y/C282Y) homozygous genotype. Hepatol Int. 2018;12(2):83-6.

12. Dong C, Yu B. Mutation surveyor: an in silico tool for sequencing analysis. Methods Mol Biol. 2011;760:223-37.

13. Minton JA, Flanagan SE, Ellard S. Mutation surveyor: software for DNA sequence analysis. Methods Mol Biol. 2011;688:143-53.

14. Richards S, Aziz N, Bale S, Bick D, Das S, Gastier-Foster J, et al. Standards and Guidelines for the Interpretation of Sequence Variants: A Joint Consensus Recommendation of the American College of Medical Genetics and Genomics and the Association for Molecular Pathology. Gene Med. 2015;17(5):405-24.

15. Zhang W, Xu A, Li Y, Zhao S, Zhou D, Wu L, et al. A novel SLC40A1 p.Y333H mutation with gain of function of ferroportin: a recurrent cause of haemochromatosis in China. Liver Int. 2019;39(6):1120-7.

16. Zhang W, Wang X, Duan W, Xu A, Zhao X, Huang J, et al. HFE-Related Hemochromatosis in a Chinese Patient: The First Reported Case. Front Genet. 2020;11:77.

17. Neghina AM, Anghel A. Hemochromatosis genotypes and risk of iron overload-a meta-analysis. Ann Epidemiol. 2011;21(1):1-14.

18. Sandhu K, Flintoff K, Chatfield MD, Dixon JL, Ramm LE, Ramm GA, et al. Phenotypic analysis of hemochromatosis subtypes reveals variations in severity of iron overload and clinical disease. Blood. 2018;132(1):101-10.

19. Yeap BB, Divitini ML, Gunton JE, Olynyk JK, Beilby JP, McQuillan B, et al. Higher ferritin levels, but not serum iron or transferrin saturation, are associated with Type 2 diabetes mellitus in adult men and women free of genetic haemochromatosis. Clin Endocrinol (Oxf). 2015;82(4):525-32.

20. Creighton Mitchell T, McClain DA. Diabetes and Hemochromatosis. Curr Diab Rep. 2014;14(5):488

21. Afkhami-Ardekani M, Rashidi M. Iron status in women with and without gestational diabetes mellitus. J Diabetes Compl. 2009;23(3):194-8.

22. Sharifi F, Nasab NM, Zadeh HJ. Elevated serum ferritin concentrations in prediabetic subjects. Diab Vasc Dis Res. 2008:5(1):15-8.

23. Allen KJ, Gurrin LC, Constantine CC, Osborne NJ, Delatycki MB, Nicoll AJ, et al. Iron-overload-related disease in HFE hereditary hemochromatosis. N Engl J Med. 2008;358(3):221-30.

24. Husar-Memmer E, Stadlmayr A, Datz C, Zwerina J. HFE-related hemochromatosis: an update for the rheumatologist. Curr Rheumatol Rep. 2014;16(1):393.

25. Barton JC, Barton JC, Adams PC. Clinical and Laboratory Associations with Persistent Hyperferritinemia in 373 Black Hemochromatosis and Iron Overload Screening Study Participants. Ann Hepatol. 2017;16(5):802-11.

\section{Publisher's Note}

Springer Nature remains neutral with regard to jurisdictional claims in published maps and institutional affiliations.

Ready to submit your research? Choose BMC and benefit from:

- fast, convenient online submission

- thorough peer review by experienced researchers in your field

- rapid publication on acceptance

- support for research data, including large and complex data types

- gold Open Access which fosters wider collaboration and increased citations

- maximum visibility for your research: over 100M website views per year

At $B M C$, research is always in progress.

Learn more biomedcentral.com/submissions 